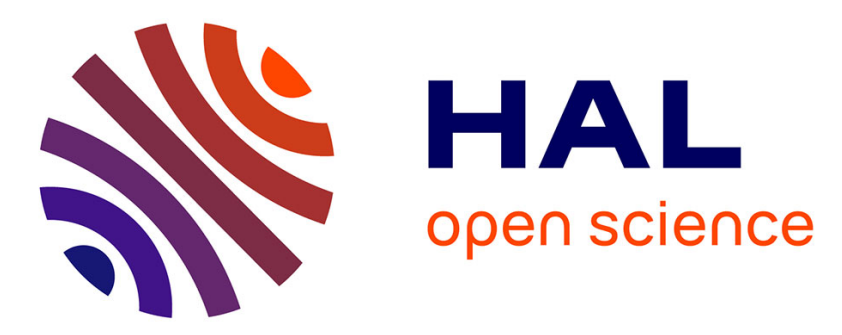

\title{
A three-dimensional organotypic assay to measure target cell killing by cytotoxic $\mathrm{T}$ lymphocytes
}

\author{
Bettina Weigelin, Peter Friedl
}

\section{To cite this version:}

Bettina Weigelin, Peter Friedl. A three-dimensional organotypic assay to measure target cell killing by cytotoxic T lymphocytes. Biochemical Pharmacology, 2010, 80 (12), pp.2087. 10.1016/j.bcp.2010.09.004 . hal-00637159

\section{HAL Id: hal-00637159 https://hal.science/hal-00637159}

Submitted on 31 Oct 2011

HAL is a multi-disciplinary open access archive for the deposit and dissemination of scientific research documents, whether they are published or not. The documents may come from teaching and research institutions in France or abroad, or from public or private research centers.
L'archive ouverte pluridisciplinaire HAL, est destinée au dépôt et à la diffusion de documents scientifiques de niveau recherche, publiés ou non, émanant des établissements d'enseignement et de recherche français ou étrangers, des laboratoires publics ou privés. 


\section{Accepted Manuscript}

Title: A three-dimensional organotypic assay to measure target cell killing by cytotoxic T lymphocytes

Authors: Bettina Weigelin, Peter Friedl

PII: $\quad$ S0006-2952(10)00660-X

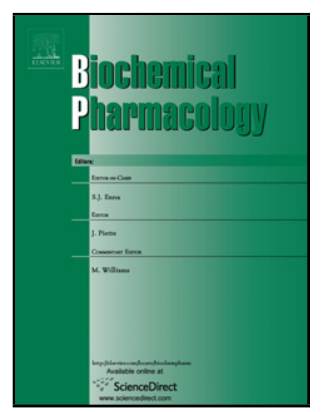

DOI: doi:10.1016/j.bcp.2010.09.004

Reference: $\quad$ BCP 10709

To appear in: $\quad B C P$

Received date: $\quad$ 11-6-2010

Revised date: $\quad 3-9-2010$

Accepted date: $\quad$ 7-9-2010

Please cite this article as: Weigelin B, Friedl P, A three-dimensional organotypic assay to measure target cell killing by cytotoxic T lymphocytes, Biochemical Pharmacology (2010), doi:10.1016/j.bcp.2010.09.004

This is a PDF file of an unedited manuscript that has been accepted for publication. As a service to our customers we are providing this early version of the manuscript. The manuscript will undergo copyediting, typesetting, and review of the resulting proof before it is published in its final form. Please note that during the production process errors may be discovered which could affect the content, and all legal disclaimers that apply to the journal pertain. 
A three-dimensional organotypic assay to measure target cell killing by cytotoxic $\mathbf{T}$ lymphocytes

Bettina Weigelin $^{\mathrm{a}}$ and Peter Friedl ${ }^{\mathrm{a}, \mathrm{b}}$

${ }^{a}$ Department of Cell Biology, Nijmegen Center for Molecular Life Science, Radboud University Nijmegen Medical Centre, P.O. 9101, 6500 HB, Nijmegen, The Netherlands

${ }^{b}$ Rudolf-Virchow Center for Experimental Biomedicine and Department of Dermatology, Venerology, and Allergology, University of Würzburg, Josef-Schneider-Strasse 2, 97080 Würzburg, Germany

Corresponding author: $\underline{\text { P.Friedl@ ncmls.ru.nl, }}$

Phone: +31.24.36 55608 (secretary) +31.24.3610907 (office) Fax: +31.24.3615317 


\begin{abstract}
Cytotoxic T lymphocytes (CTL) mediate antigen- and cell-cell contact dependent killing of target cells, such as cancer cells and virus-infected cells. In vivo, this process requires active migration of CTL towards and away from target cells. We here describe an organotypic 3D collagen matrix assay to monitor CTL migration together with CTL-mediated killing of target cells. The assay supports both, time-lapse microscopy of killing dynamics as well as population analysis of killing after matrix digestion and flow cytometry. The assay was used to assess the detrimental effect of cyclosporine A (CsA) present during CTL activation, which caused an inhibition of CTL-target cell conjugation and strongly impaired CTL-mediated killing, particularly at low effector-target ratios. Thus, the organotypic assay is useful to monitor spatiotemporal control mechanisms of cytotoxic immune effector functions.
\end{abstract}

Cytotoxic T-lymphocytes, cell migration, real-time imaging, immunotherapy, cytotoxicity assay

\title{
1. Introduction
}

Cytotoxic T lymphocytes (CTL) mediate the killing of target cells that express antigenic peptide in the context of the MHC complex and thereby eliminate virally infected and malignant cells. In the tissues, CTL-mediated cytotoxicity is a multi-step process which requires initial entry through the blood vasculature into the diseased tissue, migration towards and surface scanning of target cells followed by TCR triggering by cognate peptide/MHC complexes and stable 
conjugation. Specific TCR-induced signaling then mediates lytic granule release or the engagement of FasL death receptors with Fas on the target cell and subsequent apoptosis induction. As last step, mediated by the re-onset of migration, the CTL dissociates from the dying or already dead target cell for consecutive contacts [1]. Thus a complex series of migration, adhesive cell-cell interaction and signaling steps is integrated in a spatiotemporal manner.

Because of their ability to kill tumor cells effectively and specifically, adoptive transfer of ex vivo activated, autologous or heterologous CTL are used for anti-tumor immunotherapy. The current criteria for selection of $\mathrm{T}$ cells for adoptive immunotherapy include a high avidity for tumor-associated antigens, the capability to produce Th1 cytokines, and a potent tumor specific lytic capacity [2]. In the clinical practice however, in vitro measured anti-tumor reactivity often fails to correlate with the anti-tumor efficacy after adoptive transfer into the patient [2]. Thus, yet unidentified factors present in the tumor microenvironment counteract CTL function. CTL mediated cytotoxicity is typically studied in two-dimensional liquid cocultures of target cells and CTL $[3,4]$. However, this approach does not sufficiently reflect the in vivo situation in solid tumors and likely leads to an inaccurate estimation of CTL efficiency. Therefore, in vitro assays that mimic the interstitial characteristics of the tumor microenvironment are required to identify and routinely test additional parameters of an efficient CTL effector phase.

In the clinic, the immunosuppressive drug Cyclosporine A (CsA) is used as standard treatment to reduce CTL effector function to cope with autoimmune diseases and unwanted graft rejection. By blocking the calcium calmodulin-dependent serine/threonine phosphatase calcineurin, CsA interferes with TCR mediated activation of the transcription factor NF-AT and subsequently with the transcription of genes required for T cell activation and proliferation (e.g. IL-2) [6]. 
Calcineurin signaling supports $\mathrm{T}$ cell effector functions including degranulation and formation of the immunological synapse $[9,10]$; consequently inhibition of this pathway was shown to inhibit CTL effector function in classical CTL-mediated killing assays which use passive cosedimentation and, hence, bypass the active phase of CTL conjugation with the target cell $[8,9,10]$.

We here describe an organotypic collagen matrix-based three-dimensional assay of CTL effector function against antigenic target cells that can be used for monitoring single-cell dynamics and killing as well as population analysis of killing efficiency. To avoid the potential bias towards forced conjugation and lytic interaction introduced by passive sedimentation we here re-assessed CsA effects on CTL functions.

\section{Material and Methods}

Target cells

C57BL/6 mouse embryonic fibroblast-like cells transfected with B7.1 and a minigene encoding the OVA-derived CTL epitope SIINFEKL (MEC/OVAp) or the adenovirus type 5 E1A-derived CTL epitope SGPSNTPPEI (MEC/E1Ap) coupled to a signal-sequence which directs epitope expression to the endoplasmatic reticulum were used as target cells [5]. The cells were cultured in RPMI1640 medium (GIBCO, 21875) supplemented with 10\% FCS (SIGMA, F7524), 10 mM HEPES (GIBCO, 15630), $500 \mu \mathrm{M}$ 2-mercaptopethanol, 1\% penicillin and streptomycin (PAA, P11-010), 1\% sodium pyruvate (GIBCO, 11360), and 0,1mM non-essential amino acids (GIBCO, 11140). 
Isolation and activation of primary OT1 CD8+ T lymphocytes

Splenocytes from OT1 mice were isolated and erythrocytes were depleted by ammonium chloride $\left(0.83 \% \mathrm{NH}_{4} \mathrm{Cl}, 0.1 \% \mathrm{KHCO}_{3}, 0.37 \% \mathrm{Na}_{2}\right.$ EDTA) treatment. For the expansion of antigen-specific CTL, splenocytes were cultured at a concentration of $2.5 \times 10^{5} / \mathrm{ml}$ in the presence of $0.5 \mu \mathrm{g} / \mathrm{ml}$ SIINFEKL peptide in 24-well plates for 3 days. On day 3, IL-2 (100U/ml), either alone or in combination with Cyclosporine A (Sigma) in different concentrations was added to the cultures. Lymphocytes were incubated for further $48 \mathrm{~h}$ and harvested on day 5 by a Ficoll gradient (AXIS-SHIELD PoC AS, Oslo, Norway) - with a purity of Valpha $2^{+} \mathrm{CD} 8^{+} \mathrm{CD} 44^{\mathrm{hi}}$ cells exceeding $96 \%$, determined by flow cytometry. To determine the proliferation of CTL upon addition of IL-2 and CsA, CTL were labeled with 5 $\mu \mathrm{M}$ CFSE and proliferation was quantified as decreasing CFSE fluorescence following cell divisions.

Collagen-matrix based cytotoxicity assay

A sandwich assay consisting of target cells adherent to the bottom to the culture dish overlaid with a polymerized 3D collagen lattice containing preactivated CTL was developed (Fig. 1A). Subconfluent MEC/OVAp target or MEC/E1Ap control cells were washed with phosphatebuffered saline (PBS), labeled with either low $\left(0.4 \mu \mathrm{M}, \mathrm{CFSE}^{\text {low }}\right)$ or high $\left(8 \mu \mathrm{M} \mathrm{CFSE}^{\text {high }}\right)$ concentrations of CFSE ( 5 min, RT) to generate differentially labeled target/control cells. Cells were then washed twice with PBS, detached with trypsin/EDTA and seeded in a 1:1 ratio into 96-flat bottom wells (final density of $2 \times 10^{4} /$ well). After $4 \mathrm{~h}$ of incubation and cell attachment to form a subconfluent target cell layer, collagen solution (PureCol®, Inamed BioMaterials; $75 \mu \mathrm{l} /$ well; collagen concentration $1,7 \mathrm{mg} / \mathrm{ml}$;) containing the CD8+ T lymphocytes was added on 
top. After polymerization for $30 \mathrm{~min}$ at $37^{\circ} \mathrm{C}$, the matrix was overlaid with growth medium $(75 \mu \mathrm{l})$ and incubated for 16 to $20 \mathrm{~h}\left(37^{\circ} \mathrm{C}, 5 \% \mathrm{CO} 2\right.$, humidified atmosphere). To harvest surviving cells, the collagen was dissolved by collagenase I (40U/well; 30 min; Sigma C0130) and the remaining adherent cells detached with trypsin/EDTA (5 min). Both cell fractions were unified, stained with propidium iodide ( $5 \mu \mathrm{g} / \mathrm{ml}, 5 \mathrm{~min}, \mathrm{RT})$ washed twice with PBS, fixed in $4 \%$ PFA (30 min, RT) and analyzed by flow cytometry.

The specific killing efficiency was determined as the ratio of propidium iodide negative $\mathrm{CFSE}^{\text {low }}$ target to $\mathrm{CFSE}^{\text {high }}$ control cells and normalized to background cell death from the negative control cultured in the absence of CTL. The relative survival of CFSE ${ }^{\text {low }}$ target cells compared to $\mathrm{CFSE}^{\text {high }}$ control cells was calculated as follows: 1 - (ratio $\mathrm{CFSE}^{\text {low }} / \mathrm{CFSE}^{\text {high }}$ reference sample) / (ratio $\mathrm{CFSE}^{\text {low }} / \mathrm{CFSE}^{\text {high }} \mathrm{CTL}$ sample $)=\%$ specific killing efficiency. At least 10,000 $\mathrm{CFSE}^{+} \mathrm{PI}^{-}$events were measured from each sample.

To compare CTL viability in different samples and treatment conditions, the ratio of viable CTL to surviving CFSE ${ }^{\text {high }}$ control cells was determined. At E:T ratios below 1:2 no unspecific bystander killing of CFSE ${ }^{\text {high }}$ labeled control cells was observed, which allowed their use as internal standard for cell counting given their presence in equal numbers in all samples. To quantify CTL-target cell conjugate formation, CTL were labeled with $4 \mu \mathrm{M}$ CellTracker ${ }^{\mathrm{TM}}$ Orange (CMTMR; Molecular Probes) before coculture and CTL-target cell conjugates were determined by flow cytometry as propidium iodide negative, CFSE/CMTMR double positive events.

Time-lapse bright-field and fluorescence microscopy 
Migration of CTL in the collagen matrix and scanning of CFSE labeled target cells was recorded by fluorescence time-lapse microscopy in a Microscope Stage Incubator (Oko-Lab, Italy), ensuring optimal culture conditions, using a Nikon DiaPhot equipped with a Hamamatsu C848405G digital camera. Images were taken with a $1 \mathrm{~min}$ frame interval for up to $24 \mathrm{~h}$ using the timelapse software (Oko-Lab, version 2.7).

\section{Results}

3.1 Principle of migration-based cytotoxicity assay

The organotypic killing assay consisted of a 3D fibrillar collagen matrix containing CTL and the interface between collagen and the culture dish containing subconfluent target cells (Fig. 1A). To address whether the design supports CTL effector function together with active movement before and after target cell killing, the interface was monitored by long-term timelapse fluorescence microscopy. MEC/OVAp target cells (CFSE ${ }^{\text {low }}$ ) and MEC/E1 Ap control cells $\left(\mathrm{CFSE}^{\text {high }}\right)$ were equally well contacted by CTL which immigrated from the above collagen scaffold towards the collagen-target cell interface (Fig. 1B; supplementary information, Movie 1). Contacts of individual CTL with MEC/OVAp eventually led to target cell rounding, detachment and blebbing, followed by structural disintegration, consistent with apoptosis induction (Fig. 1B; arrowheads). Compared with MEC/E1 Ap control cells which only occasionally showed unspecific cell death, MEC/OVAp cells were preferentially contacted and killed within the $24 \mathrm{~h}$ observation period (Fig.1B). Thus, the assay supports migration-dependent 
interaction of CTL with target cells followed by apoptosis induction in target cells in an antigendependent manner.

\subsection{Quantification of CTL mediated specific killing by flow cytometry}

To achieve sufficient throughput for pharmacological and other screenings, the 3D culture system was combined with a flow cytometry read out. At the end of the incubation time the collagen matrix was dissolved using collagenase and surviving adherent target cells were detached and combined with the supernatant containing CTL and dead target cells for flow cytometric analysis. The differential $\mathrm{CFSE}^{\text {high/low }}$ label in combination with propidium iodide staining allowed to distinguish several discrete cell populations (Fig. 2A). Intact, viable CFSE ${ }^{\text {low }}$ MEC/OVAp target and CFSE ${ }^{\text {high }}$ MEC/E1Ap control cells formed two distinct propidium iodidenegative populations which were separate from $\mathrm{CFSE}^{\text {negative }}$ but weakly autofluorescent CTL (Fig. 2A). Propidium iodide-positive cells retained the initial CFSE intensity prior to structural disintegration (Fig. 2A, lower panel). The relative percentage of surviving CFSE ${ }^{\text {low }}$ MEC/OVAp target cells compared to CFSE ${ }^{\text {high }}$ MEC/E1Ap control cells was used to calculate the specific killing efficiency. Thereby, the ratio of viable $\mathrm{CFSE}^{\text {high }}$ to $\mathrm{CFSE}^{\text {low }}$ target cells at the endpoint of the assay was compared to the ratio of viable CFSE $^{\text {high }}$ to CFSE ${ }^{\text {low }}$ target cells in a reference sample without CTL.

To analyze the dose effect of CTL mediated cytotoxicity, effector and target cells were incubated in various ratios and harvested for analysis after $16 \mathrm{~h}$ of incubation. Specific killing efficiency was reliably obtained for E:T ratios of 1:16 and below. At an ET ratio of 1:1 a plateau of killing efficiency $(85 \%)$ was reached. Higher E:T ratios induced substantial unspecific collateral damage and thereby decreased the target cell number in non-cognate control cultures which 
served as internal reference to calculate the specific killing efficiency. The combination of the sensitive single cell read out and incubation times of up to $40 \mathrm{~h}$ (data not shown) allow the sensitive quantification of CTL effector pathways at low effector : target ratios.

3.3 Cyclosporine A impairs CTL effector function by reducing the ability of CTL to form stable interactions with target cells

To address the effect of CsA on in-vitro activated CTL effector function, CTL during preactivation were cultured in the absence or presence of CsA at concentrations reached in patients blood samples [7], together with IL-2. Even at high concentrations $(1 \mu \mathrm{M})$, CsA did not affect CTL proliferation or the expression levels of CD25 during pOVA-induced CTL priming (data not shown). However, in the organotypic effector function assay, CsA impaired CTL mediated target cell lysis significantly at concentrations of $0.1 \mu \mathrm{M}$ and above (Fig. 3) which led to nearcomplete abrogation of killing even at intermediate and low E:T ratio. CsA had no effect on CTL viability (data not shown) but strongly inhibited adhesive interaction of CTL with target cells. Using CTL labeled with red-fluorescent CMTMR confronted with green-fluorescent CFSElabeled target cells, a strong reduction of CFSE/CMTMR double positive CTL-target cell conjugates was obtained by flow cytometry (Fig.3B, dashed lines). The conjugation defect was dose-dependent and near-complete at high CsA concentration for both, pOVA expressing target cells and non-cognate control cells (Fig. 3C). Using time-lapse microscopy in parallel, no difference in basic migration in the collagen lattice and towards target cells was detected for CsA treated and control CTL, excluding that CsA causes a migration deficit (Supplementary Movie 2). Thus, impaired killing efficiency was a linear function of impaired CTL adhesion to target cells in the presence of CsA (Fig. 3D). 


\section{Discussion}

The 3D matrix environment of the organotypic killing assay mimics the tumor matrix interface and depends upon an active migration phase of CTL to reach and interact with target cells. Consequently, passive aggregation of CTL with target cells, which is integral to established cellsuspension based killing assays, is avoided. Further, the dense accumulation of CTL in conventional killing assays may promote unspecific killing through high local concentrations of effector molecules. In addition, the absence of fibrillar extracellular matrix structures or stable cellular networks hinders active migration and scanning of cell surfaces by CTL. In contrast, the novel migration-based system promotes the natural dynamic behavior of CTL thereby providing improved biologically relevant information on CTL effector function. Thus, all substeps of CTL mediated killing, including migration through the interstitial matrix, active conjugation with target cells including a stop-signal, and detachment from the target cell can be tested and monitored in conjunction.

The assay was validated using CsA present during the activation of effector CTL, which mimics CsA effects under steady-state conditions in patients [7]. The used doses match CsA plasma levels reached under clinical conditions which an average of $0.2 \mu \mathrm{M}$ and peak concentrations up

to $1.8 \mu \mathrm{M}$ [7]. In the ${ }^{51} \mathrm{Cr}$ release assay subtotal (80\%) inhibition of target cell lysis was described despite CsA for a dose-range up to $1 \mu \mathrm{M}$ [8], which was fully reproduced here using the 3D organotypic assay. As main difference, in contrast to the passive aggregation used in conventional CTL-mediated killing assays which preclude meaningful assessment of CTL-target cell conjugation, the 3D collagen environment requires CTL to migrate towards and actively 
approach, and detach from, target cells. Thus the natural conjugation phases are recapitulated and an overestimation of killing efficiency caused by artificial aggregation is avoided. Further, unlike the conventional ${ }^{51} \mathrm{Cr}$ release assay which is limited to 4 to $8 \mathrm{~h}$, the organotypic assay supports observation periods of up to $40 \mathrm{~h}$ which facilitates the sensitive detection of weak or delayed effector mechanisms at low effector-to-target ratios and thereby greatly better reflects the sequence of conjugation steps during CTL effector function. This new topographic element allows the meaningful combination of measuring killing efficiency with associated functions, including conjugation measured by flow cytometry and CTL migration monitored by time-lapse microscopy. This combined approach provides mechanistic insight into CTL effector function beyond the capabilities of cell-suspension based killing assays. Treatment of CTL with CsA in the presence of IL-2 leaves CTL proliferation and migration capabilities intact, however nearcompletely ablates stable conjugation with target cells and, consequently cytotoxic outcome. This finding complements previous observations of a CsA mediated reduction of CD3/TCR relocalization to the T cell-target cell interface [9] and is consistent with an impaired timely formation of the cytolytic effector synapse [11].

Because of its tissue-based organization, this assay will be amenable to further mechanistic studies on effector CTL functions, including the detection of cell surface markers to characterize surviving target cell subpopulations; intracellular staining of cytokine expression profiles of the immune effector cells; and to determine the cell cycle stage of surviving target cells based on propidium idodide labeling. If combined with fixation and antibody staining in parallel cultures, additional information of cell-cell conjugation and the immunological synapse can be retrieved (own unpublished observations) providing additional information on effector-target cell conjugation and the mechanisms of CTL mediated apoptosis induction. This will allow to screen 
for factors modulating CTL efficiency, including factors that affect dynamic CTL migration and antigen-and costimulation dependent cell-cell adhesion with adequate throughput. Thus, the organotypic CTL function assay will be useful to establish and monitor optimized tumor-reactive CTL for adoptive immunotherapy as well as for pharmacological screenings in the development of efficient and selective immunosuppressive or -activating drugs.

\section{Acknowledgements}

This work was supporrted by grants from the DFG (FR1155/8-3) and the EU (FP7, ENCITE HEALTH TH-15-2008-208142).

\section{References}

[1] Friedl P, Weigelin B. Interstitial leukocyte migration and immune function. Nat Immunol 2008; 9:960-9.

[2] Gattinoni L, Powell DJ, Jr.Rosenberg SA, Restifo NP. Adoptive immunotherapy for cancer: building on success. Nat Rev Immunol 2006; 6:383-93.

[3] Jedema I, van der Werff NM, Barge RM, Willemze R, Falkenburg JH. New CFSE-based assay to determine susceptibility to lysis by cytotoxic T cells of leukemic precursor cells within a heterogeneous target cell population. Blood 2004; 103:2677-82. 
[4] Brunner KT, Mauel J, Cerottini JC, Chapuis B. Quantitative assay of the lytic action of immune lymphoid cells on 51-Cr-labelled allogeneic target cells in vitro; inhibition by isoantibody and by drugs. Immunology 1968; 14:181-96.

[5] Schoenberger SP, Jonges LE, Mooijaart RJ, Hartgers F, Toes RE, Kast WM, et. al. Efficient direct priming of tumor-specific cytotoxic T lymphocyte in vivo by an engineered APC. Cancer Res 1998; 58:3094-100.

[6] Ho S, Clipstone N, Timmermann L, Northrop J, Graef I, Fiorentino D, et.al. The mechanism of action of cyclosporin A and FK506. Clin Immunol Immunopathol 1996; 80:40-4.

[7] Halloran PF, Helms LM, Kung L, Noujaim J. The temporal profile of calcineurin inhibition by cyclosporine in vivo. Transplantation 1999; 68:1356-61.

[8] Zhan X, Brown B, Slobod KS, Hurwitz JL. Inhibition of ex vivo-expanded cytotoxic Tlymphocyte function by high-dose cyclosporine.Transplantation 2003; 76:739-40.

[9] Zeyda M, Geyeregger R, Poglitsch M, Weichhart T, Zlabinger GJ, Koyasu S,et.al.. Impairment of $\mathrm{T}$ cell interactions with antigen-presenting cells by immunosuppressive drugs reveals involvement of calcineurin and NF-kappaB in immunological synapse formation. $\mathrm{J}$ Leukoc Biol 2007; 81:319-27.

[10] Dutz JP, Fruman DA, Burakoff SJ, Bierer BE. A role for calcineurin in degranulation of murine cytotoxic T lymphocytes. J Immunol 1993; 150:2591-8.

[11] Friedl P, Storim J. Diversity in immune-cell interactions: states and functions of the immunological synapse. Trends Cell Biol 2004; 14:557-67. 


\section{Figure legends}

Figure 1: Visualization of CTL migration dynamics and target cell killing. (A) 3D collagen assay setup. Monolayers of $\mathrm{CFSE}^{\text {low }}$ target and $\mathrm{CFSE}^{\text {high }}$ control cells (in 1:1 ratio), were overlaid with a collagen matrix containing CTL. The three-dimensional matrix prevents passive aggregation of CTL and target cells and instead promotes the natural migration behavior of CTL. (B) CTL mediated killing of target cells, monitored by time-lapse epifluorescence and bright field microscopy. MEC/OVAp target cells $\left(\mathrm{CFSE}^{\text {low }}\right)$ and MEC/E1Ap control cells (CFSE ${ }^{\text {high }}$ ) were cocultured with in vitro activated CTL from OT1 mice. Time-lapse movies were recorded for up to $24 \mathrm{~h}$ with a frame rate of $1 / \mathrm{min}$. The combination of bright field and fluorescence microscopy allowed the detection of specific apoptosis induction in target cells (indicated by membrane blebbing) during or after CTL interactions and effector function. Areas of apoptotic target cells are indicated by red crosses.

Figure 2: Quantification of antigen-specific target cell killing by flow cytometry. (A) Flow cytometric read out. Dot plots were gated on morphologically intact cells. The differentially CFSE labeled target and control cells were distinguished from CFSE negative CTL, with propidium iodide staining discriminating viable, intact from dead subpopulations. At E:T ratios of 2:1 and greater unspecific cell death was observed in control cells through bystander effects. The histograms depict the viable CFSE positive target cell populations. The relative percentage of surviving $\mathrm{CFSE}^{\text {low }}$ target cells to $\mathrm{CFSE}^{\text {high }}$ control cells served to calculate the specific killing efficiency. (B) Dose-response curve. Increasing numbers of CTL were cocultured with stable 
numbers of target cells and harvested for analysis after $16 \mathrm{~h}$ of incubation. Data represent the means $+/$ - standard deviation of at least 4 independent experiments.

Figure 3: Cyclosporin A reduces CTL:target cell conjugation and killing in the organotypic assay. Activated CTL were cultured for $48 \mathrm{~h}$ with IL-2 and CsA at different concentration and tested for killing efficiency in the organotypic assay. (A) Dose-dependent inhibition of specific killing in the presence of CsA. CsA concentrations of $0.1 \mu \mathrm{M}$ and $1 \mu \mathrm{M}$ resulted in significantly reduced CTL killing efficiencies after $16 \mathrm{~h}$ of coculture with target cells and in presence of CsA. For improved sensitivity at low effector :target (E:T) ratios (1:32 and below) the duration of coculture was $40 \mathrm{~h}$ and otherwise $16 \mathrm{~h}$. Data represent the means +/- SEM of at least 3 independent experiments. (B) Flow-cytometric detection of CTL- target cell conjugate formation in the absence (DMSO solvent) or presence of CsA. Gating of CMTMR labelled CTL (dashed box) either as CMTMR single-positive cells without conjugation (M1) or as CFSE/CMTMR double positive CTL-target cell conjugates with MEC/OVAp target cells (M2) or MEC/E1Ap control cells (M3) (C) Ratio of conjugated and unconjugated CTL with MEC/OVAp target or MEC/E1Ap control cells (3 independent experiments) (D) Correlation (r) of CTL conjugation with target cells and killing efficiency (Spearman's correlation test). (C, D) Frequency of conjugates and killing efficiency are shown as means +/- SD from 3 independent experiments.

\section{Supplementary Information}

Movie 1. Time-lapse fluorescence and bright field microscopy of CTL migration, interaction with target cells and cytotoxic effector function in the 3D organotypic killing 
assay. MEC/OVAp target cells (CFSE $\left.{ }^{\text {low }}\right)$ and MEC/E1Ap control cells (CFSE ${ }^{\text {high }}$ ) were seeded in a 1:1 ratio and overlaid with a collagen matrix containing in vitro activated CTL from OT1 mice. Time-lapse movies were recorded for up to $24 \mathrm{~h}$ with a frame rate of $1 / \mathrm{min}$. The CTL were actively migrating from the $3 \mathrm{D}$ collagen matrix towards the collagen-target cell interface, scanned and engaged with target cell surfaces. Conjugations with CFSE $^{\text {low }}$ target but not $\mathrm{CFSE}^{\text {high }}$ control cells were followed by apoptosis, including membrane blebbing of the target cells and detachment from the substrate.

\section{Movie 2. Time-lapse bright field microscopy of CsA $(1 \mu \mathrm{M})$ treated CTL migration and interaction with target cells in the 3D organotypic killing assay. MEC/OVAp target cells} were overlaid with a collagen matrix containing CTL pre-treated with $1 \mu \mathrm{M}$ CsA and IL-2 for 48h. Time-lapse microscopy was performed for up to $24 \mathrm{~h}$ with a frame rate of $2 / \mathrm{min}$. CTL actively migrated in the 3D collagen matrix and scanned target cell surfaces. In the presence of CsA, these contacts, however failed to induce target cell apoptosis. 


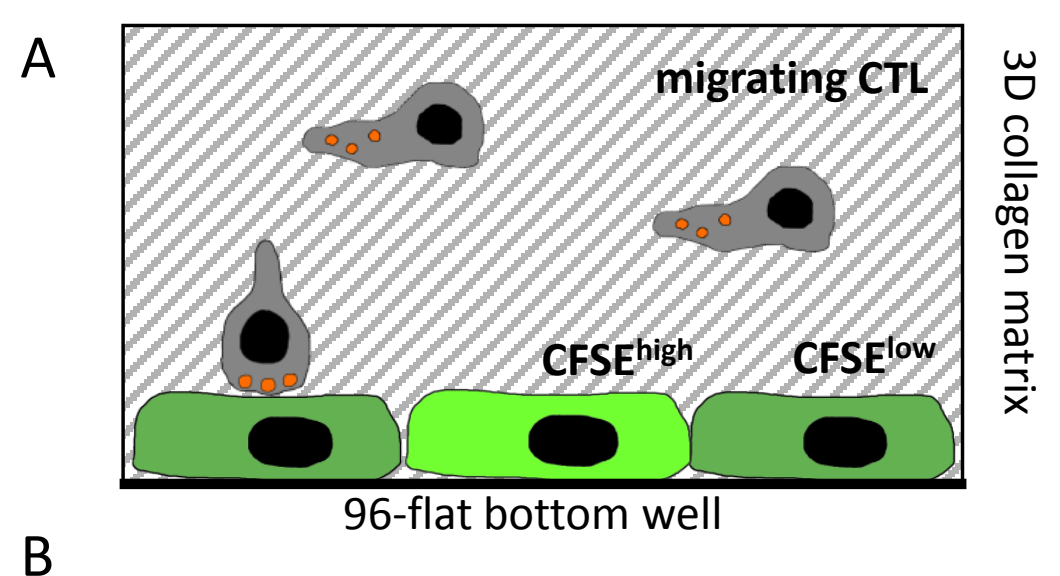

B

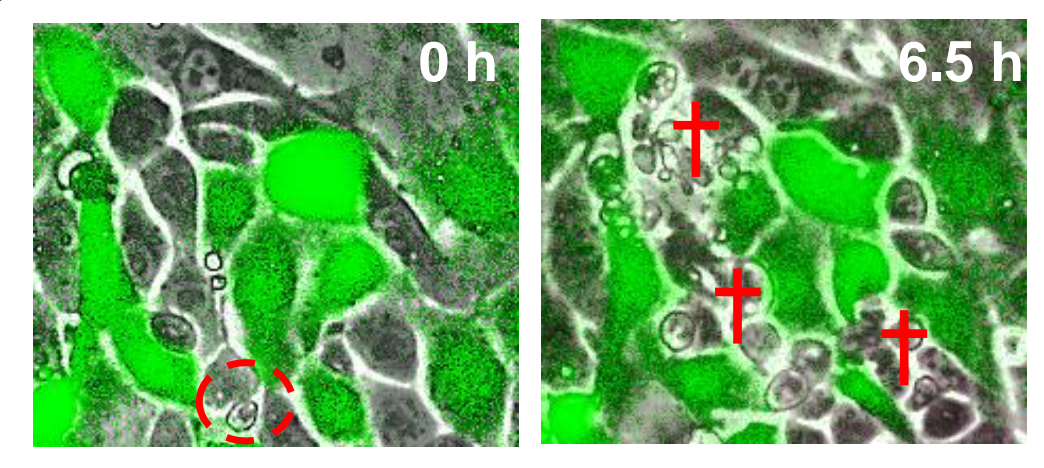

Figure 1 


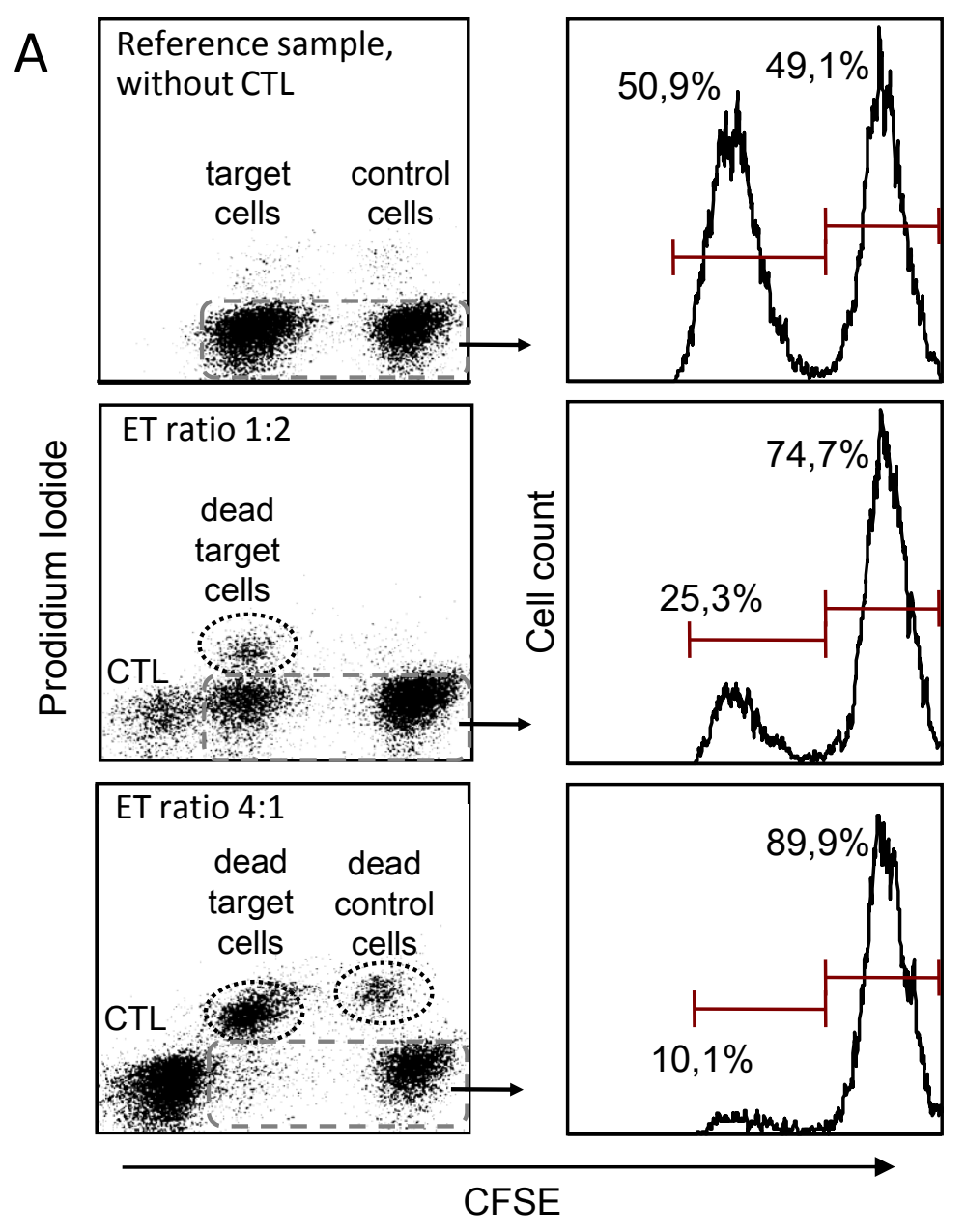

B

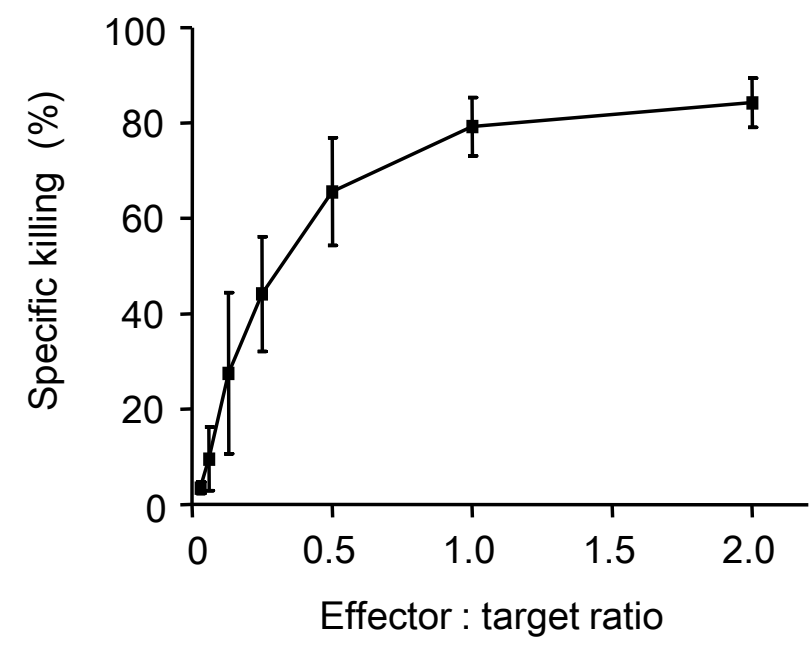

Figure 2 
A

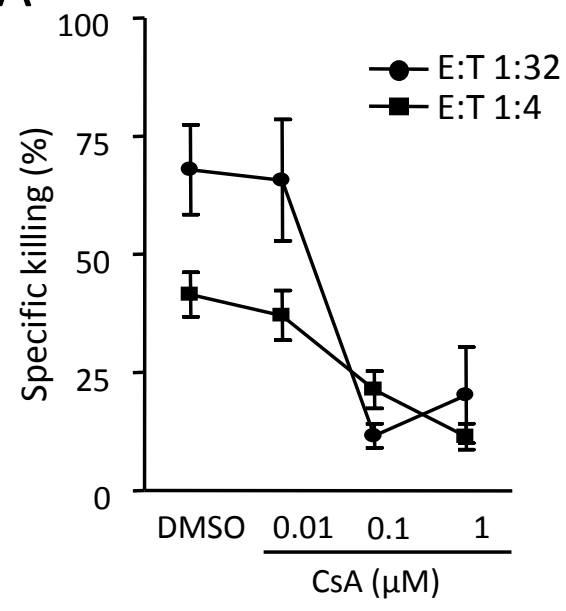

C

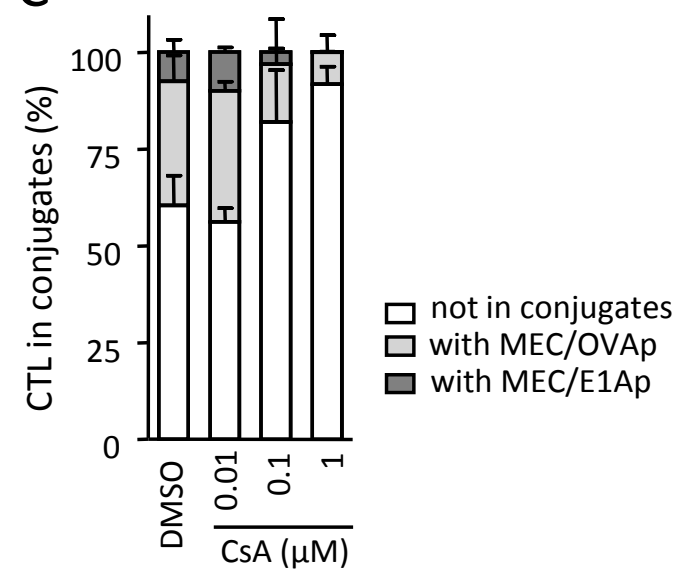

B
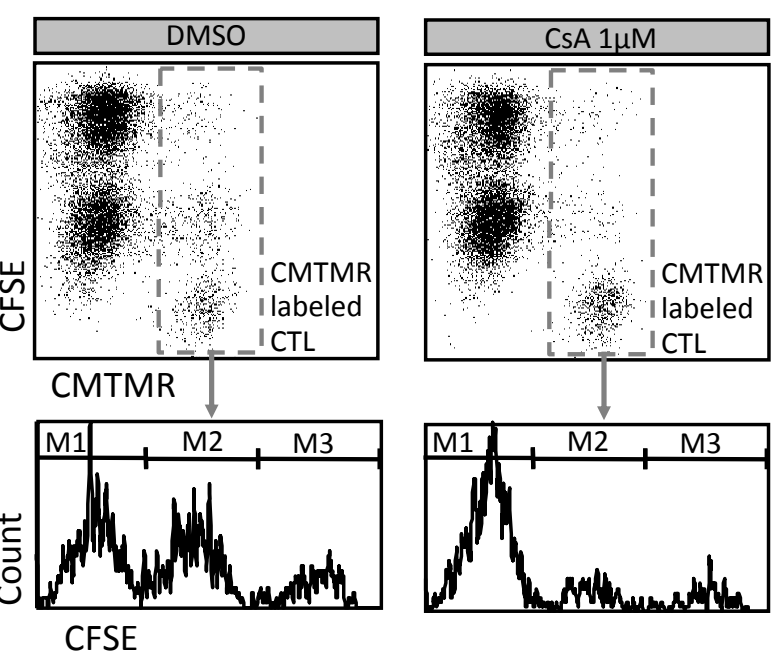

D

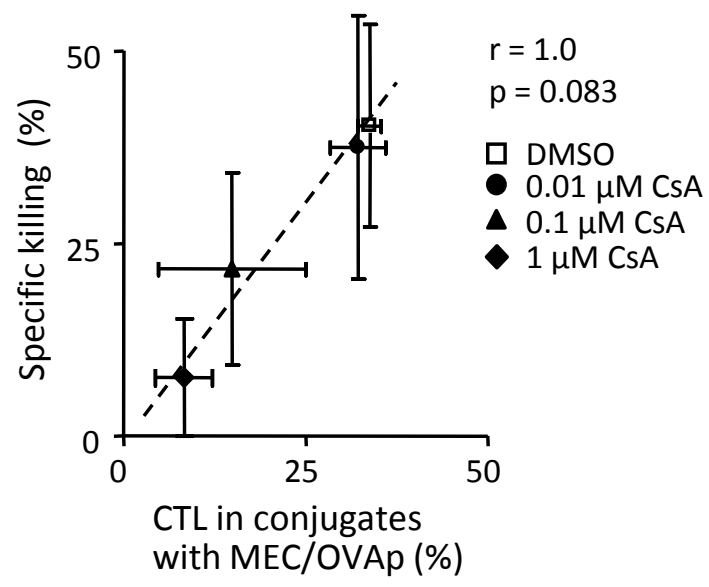

Figure 3 
We here describe an organotypic 3D collagen matrix assay to monitor CTL migration, conjugation and killing of target cells which is suitable for pharmacological compound analysis.

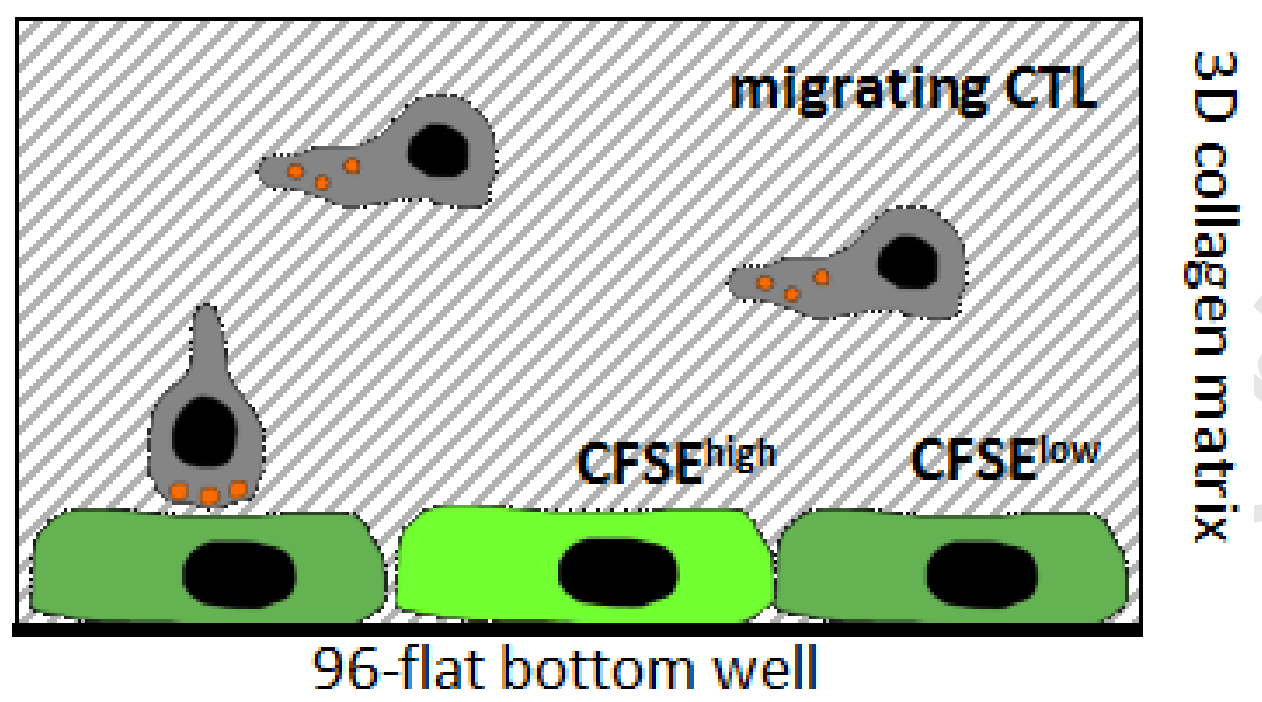

